\title{
Levels of Narrativity in Scandinavian Bronze Age Petroglyphs
}

\section{Michael Ranta, Peter Skoglund, Anna Cabak Rédei \& Tomas Persson}

\begin{abstract}
In Europe, Scandinavia holds the largest concentration of rock art (i.e. petroglyphs), created c. 5000-first century BC, many of them showing figurative and seemingly narrative representations. In this paper, we will discuss possible narratological approaches applied to these images. We might reasonably distinguish between three levels of pictorial narrativity: representations of (i) single events, understood as the transition from one state of affairs to another, usually involving (groups of) agents interacting; (ii) stories, e.g. particular sequences of related events that are situated in the past and retold for e.g. ideological or religious purposes; and (iii) by implication, master-narratives deeply embedded in a culture, which provide and consolidate cosmological explanations and social structures. Some concrete examples of petroglyphs will be presented and analysed from narratological and iconographical perspectives. We will as a point of departure focus on (i), i.e. single events, though we shall also further consider the possibility of narrative interpretations according to (ii) and (iii).
\end{abstract}

\section{Introduction}

Rock carvings, rock art, or petroglyphs are images created by removing parts of a rock surface by incising, picking, carving, or scratching, normally using lithic flakes or hammerstones as tools. Such petroglyphs, which should be distinguished from petrographs, i.e. images such as cave paintings drawn or painted on rock surfaces, can be found all over the world (except for Antarctica) (Bednarik 2012). In Europe, the largest concentration of petroglyphs can be found in Scandinavia, with rock art in the north which can be dated to 5000-first century BC and in the south to 2000-200 BC. There are about 30,000 registered sites, c. 20 per cent of them with figurative images and the rest consisting of nonfigurative configurations such as cup marks (Goldhahn \& Ling 2013, 270).

As to the motifs of the figurative images, we may discern representations of human figures, foot soles, prey and domestic animals, wagons, weapons and tools, sun crosses/sun-symbols and ships (cf.
Helskog 2012; Goldhahn \& Ling 2013; Ling 2012; Skoglund et al. 2015). Moreover, the constellations and renderings of such figures are often vivid and dynamic, showing fishing or hunting activities, combat scenes and many other forms of social (inter-) action (cf. Fig. 1).

The first attempts to document the various manifestations and sites of rock art had begun already during the seventeenth century, with more systematic investigations from the 1790s onwards (cf. Bertilsson 2015). While these investigations often had an inventory character, frequently concerned with descriptive and dating issues, increased efforts to understand the deeper meaning of these pictorial configurations, to provide interpretations of them, started during the twentieth century. Here, anthropological and historical sources from Indo-European mythology as well as Old Norse Sagas were taken into account, and petroglyphs were more or less assumed to illustrate or reflect these (for example, religious myths focusing on the rebirth and worship of the sun: see e.g. Kristiansen 2010 below). 


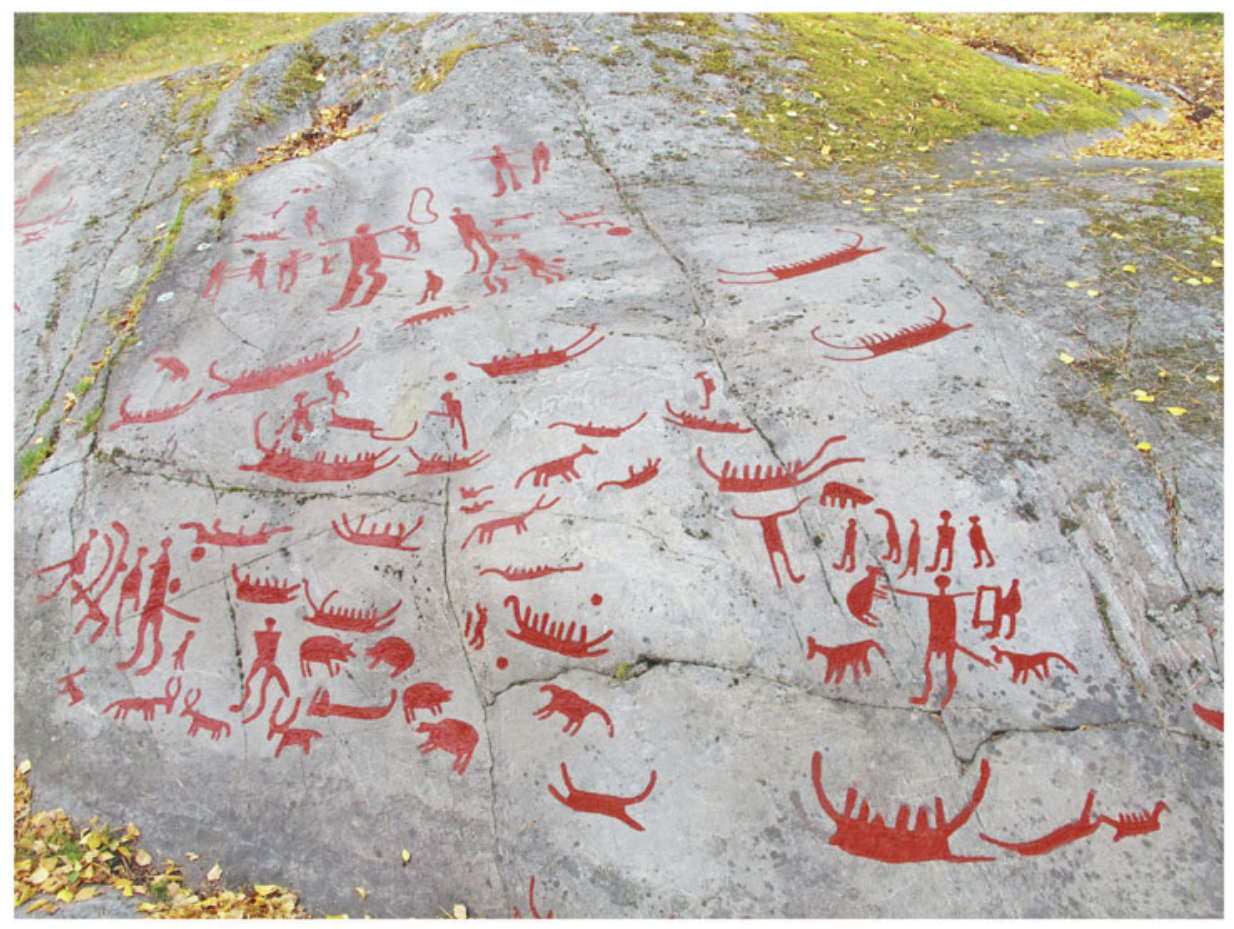

Figure 1. Boglösa 94, Enköping, Sweden: panel showing various forms of activities with possible narrative ingredients. (Photograph: Michael Ranta.)

Generally speaking, many researchers discussing various rock-art traditions in Scandinavia have claimed that rock art may show narrative configurations. For example, Knut Helskog, discussing images of bears and bear tracks on panels close to Alta in northernmost Norway, argues that these point to stories about meanings and rituals attributed to the bears (Helskog 2012). Jan Magne Gjerde, also studying the northern tradition, suggests that Stone Age rock art depicts stories based on real-life activities, though also intertwined with a prevailing cosmography (Gjerde 2010, 454). In his analysis of the carvings at the Sagaholm mound in southern Sweden, Joakim Goldhahn discusses the images and the grave itself in terms of 'narrative metaphors' related to various aspects of a Bronze Age cosmology (Goldhahn 2016).

An influential study on the narrative aspects of Late Bronze Age iconography is Flemming Kaul's work on decorated bronze razors (Kaul 1998). By examining the motifs on the razors he was able to demonstrate that individual motifs on different razors were logically linked to each other into a larger narrative revealing the travels of the sun through the sky during the day and beneath the sea at night. At different points on its journey, the sun was helped by various agents such as a sun horse, a fish and a snake, which all held specific functions within the narrative. The designs on individual artefacts depict particular stages in that cycle, and only when several razors are put together is the whole cycle revealed. It seems as if all the drawings found on decorated metalwork illustrate sections of the same story (Kaul 2005, 138).

Kaul's study was followed up by Kristian Kristiansen, who carried out an analysis of the sun journey in Bronze Age rock art in southern Scandinavia. He argues that this story is based upon a widely shared Indo-European myth about a sun maiden and her twin brothers who, in disguise of ships and horses, come to her help so that the sun can rise in the morning. Furthermore, Kristiansen was able to identify singular motifs in rock art as well that relate to the overall narrative of the journey of the sun (Kristiansen 2010).

In addition, we might mention Åsa Fredell's (e.g. 2003) semiotically and narratologically inspired studies of rock carvings. While arguing that much rock art indeed has narrative features, one of her studies (Fredell 2006) also reveals the risks involved when attempting to attribute clear-cut epic structures to these carvings. In this study, she tentatively suggests a narrative interpretation inspired by the medieval Irish epic Táin Bó Cúailnge of some rock panels in southern Sweden from late Bronze Age. However, at least in written form, this tale did not exist until 
about 1000 years after the carvings in question (although oral versions might have existed earlier).

These and other examples demonstrate that rock-art researchers often assume that rock art to some extent has a narrative character, due to perceived similarities between the depicted objects and actions in rock art and stories known from written sources, seemingly indicating that similar kinds of stories also are displayed in different kinds of media. Also actions, and traces of actions, like the bear hunts and bear tracks discussed by Helskog, have been regarded as indicative of narrative structures. To some extent, one might say, top-down approaches have been employed, where wider narratives have been projected onto the displayed images. Hereby the narrative potential of rock art has almost been taken for granted, without any thorough consideration of e.g. cognitive, semiotic, and narratological issues involved. We believe, however, that rock-art studies may benefit from studies in narratology, which has emerged as a focused research area within the humanities during the last 50 years, most notably among literary analysts, linguists, film scholars and semioticians.

In this paper, we shall discuss what constitutes narrativity in non-verbal, visual media, such as rock art. Thus we will bridge work in archaeology and, more explicitly, narratology in order to open up new perspectives for investigating the storytelling potential of pictures from long-gone cultures, though rather from a bottom-up perspective, looking at some of the very foundations for storytelling in pictures. The purpose of this paper is twofold. First, we will discuss works on narratology and cognitive psychology in order to evaluate their fruitfulness in relation to Scandinavian rock art; secondly, we will apply these approaches to a cluster of images on the rock art site at Himmelstalund in Sweden. Lastly, our strategy may contribute to:

1. a broadening of the narrative corpus in Scandinavian rock art, since our approach also allows for the inclusion of rather simple events and actions as narratives;

2. a differentiation of various kinds of narrative structures in Scandinavian rock art;

3. the establishment of a set of criteria which can be used to identify narrative structures in rock art.

\section{Narratives in static pictures}

Are rock-art pictures actually telling stories, and if so, to what extent? At a first glance, it certainly does not seem too far-fetched to suspect that petroglyphs are intended to tell some kind of stories or-at leastto represent simple event sequences. But how can we know for sure if stories are told, which ones exactly, and what kind of evidence for various interpretative hypotheses can be provided? Without doubt, storytelling is a phenomenon that occurs across all individuals within all cultures. It is unlikely that Scandinavian Bronze Age societies would have been exceptions in this respect. Cultural variations as to specific subject matters aside, the capacity and practice of storytelling seems to be a human cultural universal that serves to create and uphold existential and social order. Because of the explanations and answers they give us, explicitly or implicitly, narratives may contribute to the consolidation and reinforcement of these orders.

What, though, is a narrative? The narratologist Gerald Prince, for example, suggests the following minimal condition: 'the representation of at least two real or fictive events or situations in a time sequence, neither of which presupposes or entails the other' (Prince 1982, 4). Among narratologists no consensus exists, however, regarding the exact definition of narrative. Normally the overt representation of a sequence or series of events is considered essential (cf. Rudrum 2005, 203), but perhaps even the representation of only a single event, as suggested by Gérard Genette (1982), might be a sufficient criterion for a narrative, a question to which we will return later below. Although most studies have focused on verbal narratives, there is no reason to believe that stories are limited to verbal language, i.e. a system built on conventional signs (symbols), grammar and praxis. On the contrary, we believe that there are good reasons to assume that stories may also be expressed by other semiotic resources, such as pictures, i.e. iconic signs (icons) that are interpreted by way of their similarity to what they depict. This potential thus also exists in media which do not always show any (clear) temporal division, such as static pictorial representations. Indeed, many examples of pictorial storytelling can be found throughout history and across the world (e.g. in ancient Egypt, Greece, the Renaissance, as well as in India, China, and South America; cf. Ranta 2011, n. 2). Basically, we may discern at least three types of pictorial storytelling:

1. Serial pictures consisting of multiple distinct pictures, each of which is showing a single scene or event, that are linked in a narrative series with a fixed reading order, often horizontally or vertically arranged (see Fig. 2).

2. Single pictures that show disparate events and persons in the same pictorial space. These are 


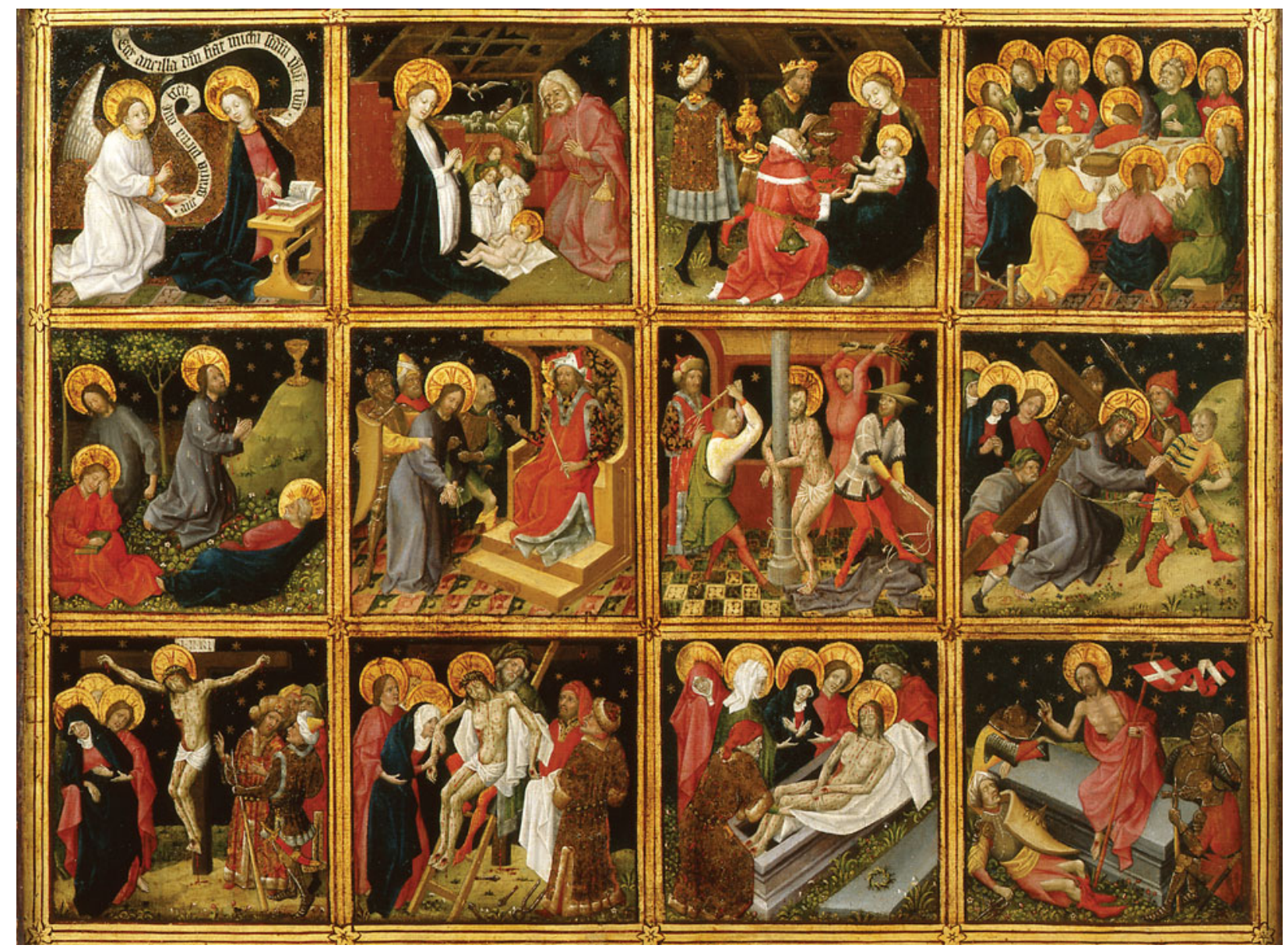

Figure 2. Unknown master: 'Life of Christ' (1450-60), Wallraf-Richartz-Museum, Cologne. (Photograph: ( Rheinisches Bildarchiv Köln, rba_d000090.)

sometimes called 'continuous narratives,' 'simultaneous succession', or 'polyphase pictures' (see Fig. 3, where St Peter is represented three times in the same pictorial space).

3. Single pictures in which an entire story is cut down into, or implied by, an isolated scene or event. These are sometimes referred to as 'monophase' or 'monoscenic' pictures (cf. Ranta 2011; 2013; see Figure 7, below).

Quite obvious cases of serial pictorial storytelling are, of course, contemporary comic strips, but throughout history numerous further examples can be found, such as reliefs from the Neo- Assyrian period (911-609 вс), the scenes from the Old and New Testaments on the bronze doors of Hildesheim Cathedral (c. 1015), the Bayeux Tapestry (1070s), or in paintings such as the Life of Christ (c. 1450-60: Fig. 2.) What these examples have in common, apart from their relatively clear sequential structuring, is that previous acquaintance with verbally communicated stories seems necessary for a detailed comprehension of the narrative. Indeed, for Figure 2, one needs to know about the life and passion of Christ as rendered in the Gospels. For media involving static images, relevant background knowledge might be necessary not only for identifying figures and objects, but also, importantly, for decoding significant or decisive moments within wider story arcs, implicitly stretching backwards and forwards in time. In short, such knowledge would be crucial in order to comprehend what exactly 'happens' in the picture sequence. Pictorial narratives in these cases have thus a more or less illustrative function, presupposing acquaintance with external textual sources, comments, and other paratextual elements. Verbal titles, such as 'Life of Christ', further aid the viewers to situate the images in a particular narrative setting.

Still, for our purposes here it is important to mention that Figure 2 can also be interpreted as a narrative structure without knowing the exact 


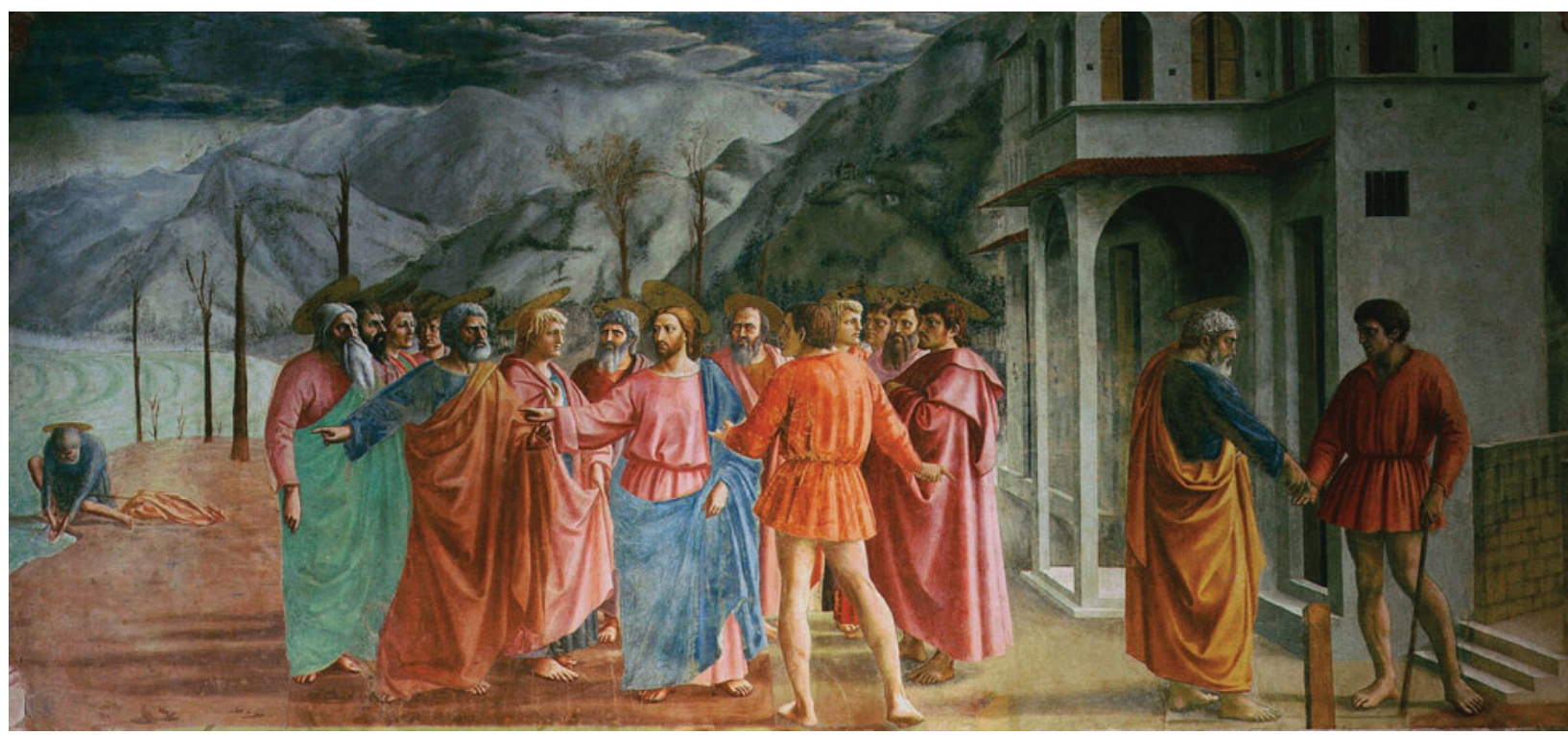

Figure 3. Masaccio: 'Tribute Money' (1424-28), Brancacci Chapel of the Basilica of Santa Maria del Carmine, Florence. (Photograph: https://commons.wikimedia.org/wiki/File:Masaccio7.jpg)

story. Even without any familiarity with the Gospels, viewers could be inclined to interpret the scenes as sequentially and progressively ordered, with recurring and visually similar figures and, perhaps, existentially significant situations, such as birth, life and death. Drawing on shared acquaintance with humans' general ways of life, viewers would probably be able to infer at least a sketchy narrative structure from the images.

We may also note that Western paintings from the Middle Ages and onwards typically seem to presuppose a singular, imagined ideal viewing position presupposed by the artist. The archaeologist Liliana Janik, when outlining a 'methodology of seeing' (inspired by the work of the perceptual psychologist Margaret Hagen), refers to this as a station point:

Station points are determined by the direction in which the artist was looking at the object or landscape and conveyed the representation of it onto canvas or rock. Understanding this allows us to follow the artist in how to look at the picture, as if we were being guided by historical and prehistorical artists as we view the creations. (Janik 2014, 109; cf. also Hagen 1986)

Before modernism, paintings frequently implied a single station point; since cubism, however, multiple station points were used, e.g. in works by Picasso, Braque and Matisse.

Something similar also seems to be the case with rock carvings, where multiple station points may be implied, as we shall see below. An additional problem is the fact that petroglyphs are not always consistently displayed in a serial or linear manner (which would facilitate narrative interpretations). Narrative readings are therefore far more difficult to accomplish. The images sometimes overlap, have different dates of origin and are frequently evocative, heterogeneous and ambiguous. Moreover, for Scandinavian Bronze Age societies, no direct external sources, such as texts, are available which might support detailed interpretations. Instead, researchers have to rely solely on the pictures themselves, in combination with clues such as mythological beliefs presumed to have been widespread during this period. Some context may be provided by assuming a certain socio-geographical background and setting, and comparisons to other contemporary artefacts, such as weapons, or bronze razors which have ornamental images similar to petroglyphs (cf. Kaul 1998). Undoubtedly, many figures seem to be intentionally clustered, organized in groups that seemingly at some point in time must have made sense to the community in which they were created. Not surprisingly, then, a wide variety of interpretations concerning the meaning of rock carvings have been suggested, according to which they are supposed to represent (i) historical events; (ii) magicalreligious beliefs and incantations; (iii) social positions and constellations; and (iv) ritual initiations, just to mention a few examples (cf. Goldhahn \& Ling 2013, 272-4). 
In rock-art studies, the concept of narrative is often reserved for panels displaying scenes which are linked to each other by (seemingly) the same subject being repeated, indicating that the various scenes are related to each other in a temporal sequence. Such examples are, for example, the bear hunt at Bergbukten in Alta (Helskog 2012), the combat scene at the Fossum panel in Tanum (Melheim 2013) and the interpretations of the movement of the sun displayed on metal objects and on rock art mentioned earlier (Kaul 1998; Kristiansen 2010). However, and inspired by Genette (1982), we propose that also very 'simple' scenes displaying single events may stand for larger narratives. Also, it should be underlined that overtly manifested linearity is not a requirement for something to be narrative; narrative images could be related to each other in multiple ways, such as in polyphase pictures.

\section{Typification}

Any straightforward attempts to identify stories in petroglyphs, then, are faced with considerable difficulties. Still, as to the identification of the depicted objects or subjects as such, one fact is striking, namely the apparent intent to create representations of real-world objects by means of visual resemblance (admittedly with varying degrees of accuracy and specificity), which we also today can often recognize and identify as such. During the last few decades, the idea that pictorial representation somehow depends on (natural) resemblance has sometimes come under attack and various scholars in the humanities have suggested that the experienced relationship of similarity between pictorial representations and the represented objects is wholly determined by cultural and historical frameworks and internalized codes, or habits of representation. Indeed, mimetic (or iconic) pictures have been claimed to be conventionalized signs, more or less comparable to linguistic items. Among the most well-known proponents of this position-which might be called pictorial conventionalism -have been, for instance, Nelson Goodman (1976), Umberto Eco (1976) and Norman Bryson (1983). The common-sense view that visual representation presupposes some kind of correspondence between picture and object in terms of (natural) resemblance or similarity is explicitly rejected by the pictorial conventionalists. We shall not be concerned here with a discussion of the arguments used against this view. Suffice it to say that the arguments put forward by radical conventionalists are unconvincing and include artificially constructed examples, where empirical findings and subjective experience as documented in disciplines such as anthropology, sociology, or psychology are largely omitted (for fuller discussions, cf. Ranta 2000, 90-101; Sonesson 1989, 220-51).

Indeed, in petroglyphs many renderings of objects and even simple actions or events may be recognizable without any detailed acquaintance with contextual circumstances, often just presupposing general life/world knowledge and the ability to decipher pictorial representations as such. However, they should hardly be seen as directly 'imitative', portrait-like representations of particular objects, subjects, or actions, as some kind of (intended) 'mirror-reflections' of an external world. Rather, these are mimetic representations of types, abstractions, or universals (rather than particulars) which may be assumed to correspond to mental representations being shared by a group of beholders. Historically seen, artists have usually adapted their work to the general cognitive abilities and presuppositions of the intended beholders. An important task of artists appears to have been to abstract and visualize those types of subjects which can be comprehended and appreciated by a larger public, that is, which provide some kind of common denominators among different beholders' mental representations. Given their placement and accessibility, rock carvings were seemingly intended to be seen by a larger audience.

Pictorial presentations in petroglyphs occur mostly on what can be called basic or subordinate typicality levels. Within cognitive psychology, it has frequently been claimed that there is a level of abstraction in category formation which is more salient than others. According to e.g. Eleanor Rosch, this level in categorization is the basic level at which objects-both biological entities and artefacts-are most commonly divided into categories (cf. Rosch \& Mervis 1975, 586). Besides the basic level, Rosch's experimentally based research suggests that we may differentiate between at least two other levels of abstraction, namely superordinate, and subordinate levels. For example, 'furniture' might count as a superordinate category, 'chair' as a basic-level one, and 'kitchen chair' or 'living-room chair' as subordinates. The basic level seems to be psychologically different from superordinates and subordinates in several ways. In contradistinction to members on a superordinate level, which have relatively few cognitively or perceptually salient characteristics in common (according to studies where subjects had to list attributes of the objects), basic-level members are regarded as resembling each other to a higher degree (i.e. they have more attributes in common). 
Furthermore, basic-level categories seem to differ from other levels of abstraction in numerous other respects (cf. Lakoff 1987, 46-7; Rosch 1994, 518-19; Rosch \& Lloyd 1978, 31-5; Rosch \& Mervis 1975, 586-7):

(i) Their members have similarly perceived overall shapes.

(ii) Their members invoke similar motor actions, that is, the way people usually interact with the objects.

(iii) They are the first categories named and learned by children (and taught by adults).

(iv) Their members are most quickly identified by subjects as belonging to a certain category.

(v) They are identified from averaged shapes of members of the class (i.e. a single pictorial image may be taken as representing the whole class). ${ }^{1}$

It seems that the overall perceived shape frequently functions as a cue for determining category membership. Accordingly, petroglyphs of ships, horses and humans might be regarded as representations of basic-level category members and spontaneously be recognized and categorized as such by modern and ancient beholders alike. Superordinates do not usually have any specific shape in common; still, we should not exclude the possibility that petroglyphs also exhibit or imply higher-level categories, though at least not immediately detectable for (untrained) contemporary beholders. For example, a picture representing a constellation of various objects, such as ships, horses, humans and so on can also imply a superordinate category such as 'mythological or supernatural space' (cf. Kristiansen 2010).

Moreover, empirical support for identifying rock-art images can sometimes be provided by comparing the petroglyphs with real objects. For instance, some depictions on rock panels show an easily recognizable resemblance to preserved wooden ards (ploughs) found in bogs (Figs. 4 \& 5).

It can be assumed, when comparing the objects with the visual displays, that the people who made the ards in the rock art used their knowledge of existing wooden ploughs. They also likely used their knowledge of the comprehensibility of petroglyphs as such. One can thereby assume that the petroglyphs in question function as iconic signs, i. e. that the rock-art image is intended to represent the wooden object visually. There are numerous other representations which can be identified as typified depictions of weapons (e.g. axes, swords, arrows), instruments (e.g. lurs) and other objects, as well as humans and animals (Nordén 1925; Skoglund 2016).

In many other cases, subordinate category members have also been depicted. Thus we can not only detect boats or humans in general, but e.g. specific fishing or war ships, and humans such as hunters, fishermen, or warriors, which are clearly subordinate categories. Another example would be a depiction of a horse drawing a sun, which refers to a mythological sun horse (a horse drawing the sun across the sky) known from contemporary metalwork, being a subordinate category member compared to the basic-level category of horses (cf. Fig. 6, with depictions of basic and subordinate members). Still, the typifying and simplifying character and appearance of petroglyphs is unmistakable, although various degrees of specificity or generality can be discerned. In general, they show a high degree of perspectival clarity, where e.g. ships and humans are shown in profile, and so on. Indeed, as research within cognitive psychology suggests, (proto-) typical representations may also include the most representational (or canonical) view of objects (cf. Palmer et al. 1981). Moreover, type-representations such as e.g. warriors are indicated by recurrent attributes (i.e. weapons such as swords or axes), males with phalluses, and musicians holding instruments such as lurs.

As indicated by our discussion, there are many examples of rock-art images displaying subordinate category members. This means that many images were meant to display not only general types, but rather specific objects and, as we shall see below, situations, which in turn add to the narrative potential of these scenes. However, it should be kept in mind that these depictions do not portray particular objects; rather, they are representations of types.

\section{Events and narratives}

As to the rendering of events or actions, we may likewise discern renderings which seem to have a typecharacter. Thus we can see scenes with humans engaging in combat, hunting, fishing, and dancing, processions and so on, in different action schemas. As already pointed out, there exists no consensus among narratologists as to defining a narrative, although the representation of events seems to lie at the core of storytelling. But must a narrative represent more than one event, and what exactly is an event? First of all, we might distinguish between different modes of being, where material objects simply exist, while events occur, happen, or take placethey might be called 'unstable objects' and are 


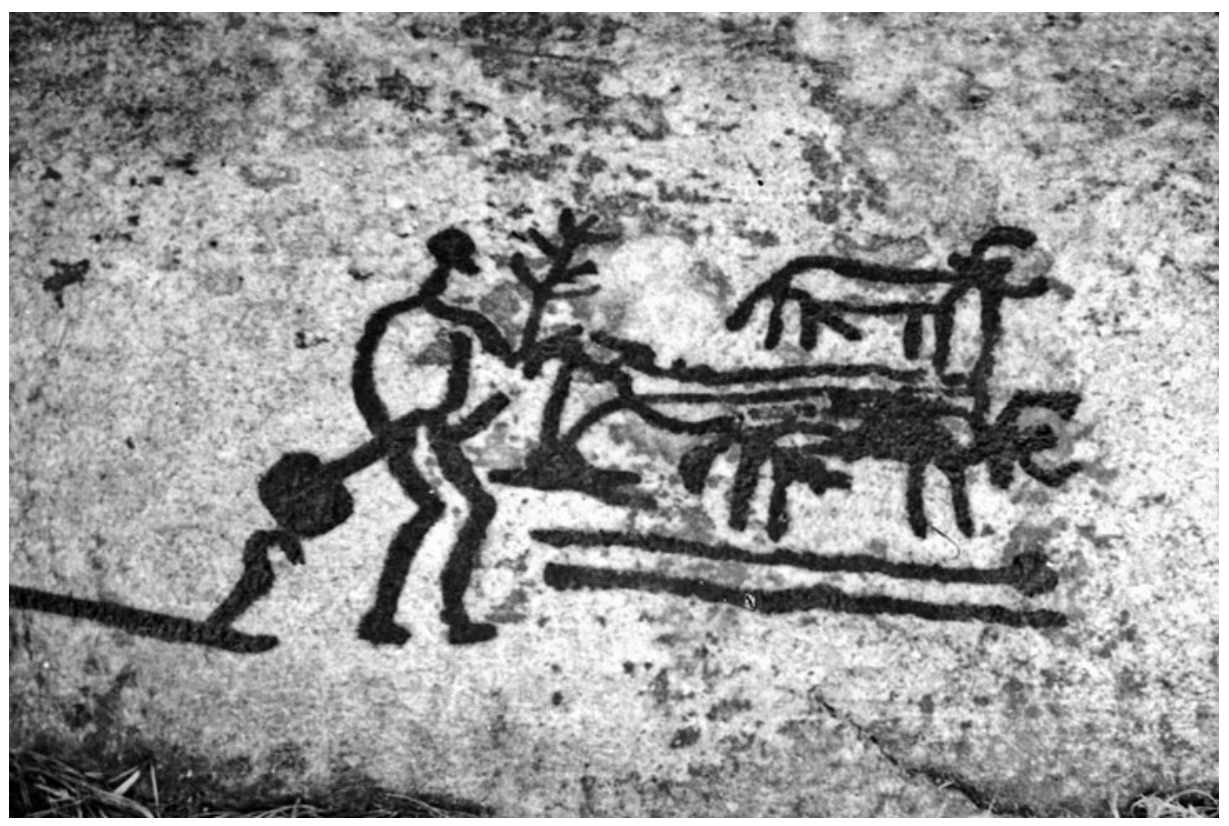

Figure 4. Man with ard and two draught animals, Litsleby, Bohuslän. SHFA Image ID 498. (Photograph: Åke Fredsjö.)

temporally extended in that they 'take up time and persist by having different parts (or "stages") at different times'. ${ }^{2}$ In addition, we might also regard event as an overarching concept, which includes goalrelated actions performed intentionally by conscious agents, but also may refer to inanimate or natural phenomena, such as earthquakes or thunderstorms. In general, any representation of a change of state, explicitly or implicitly, might be called a representation of an event.

Now, according to Genette, as we already noted, a 'narrative [can] without difficulty [be

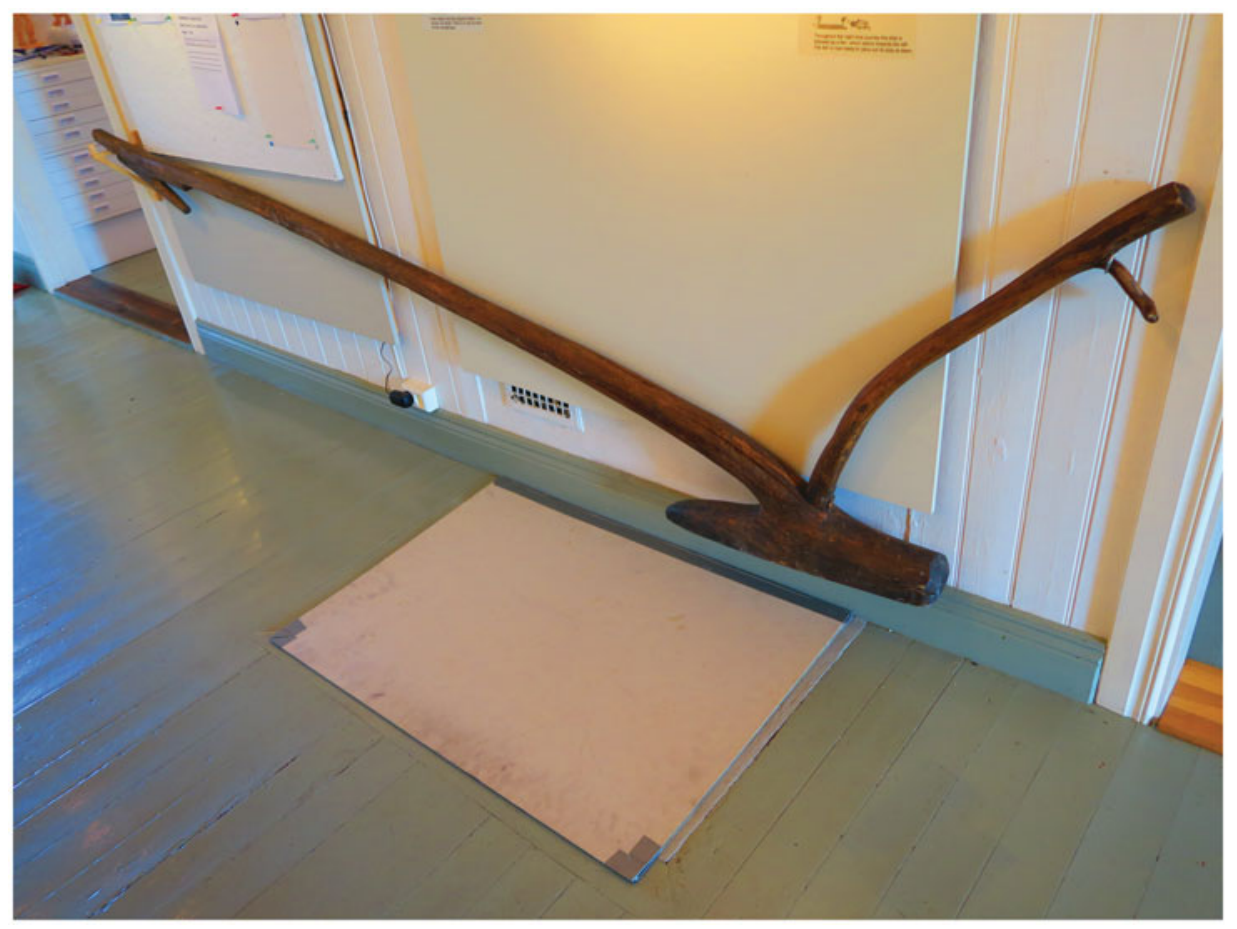

Figure 5. Replica of Bronze Age ard, Underslös Rock Carving Museum. (Photograph: Michael Ranta.) 


\section{Basic level category}

a) ship, b) horse, c) humans

\section{Subordinate level category}

d) war ship, e) sun horse, f) warriors
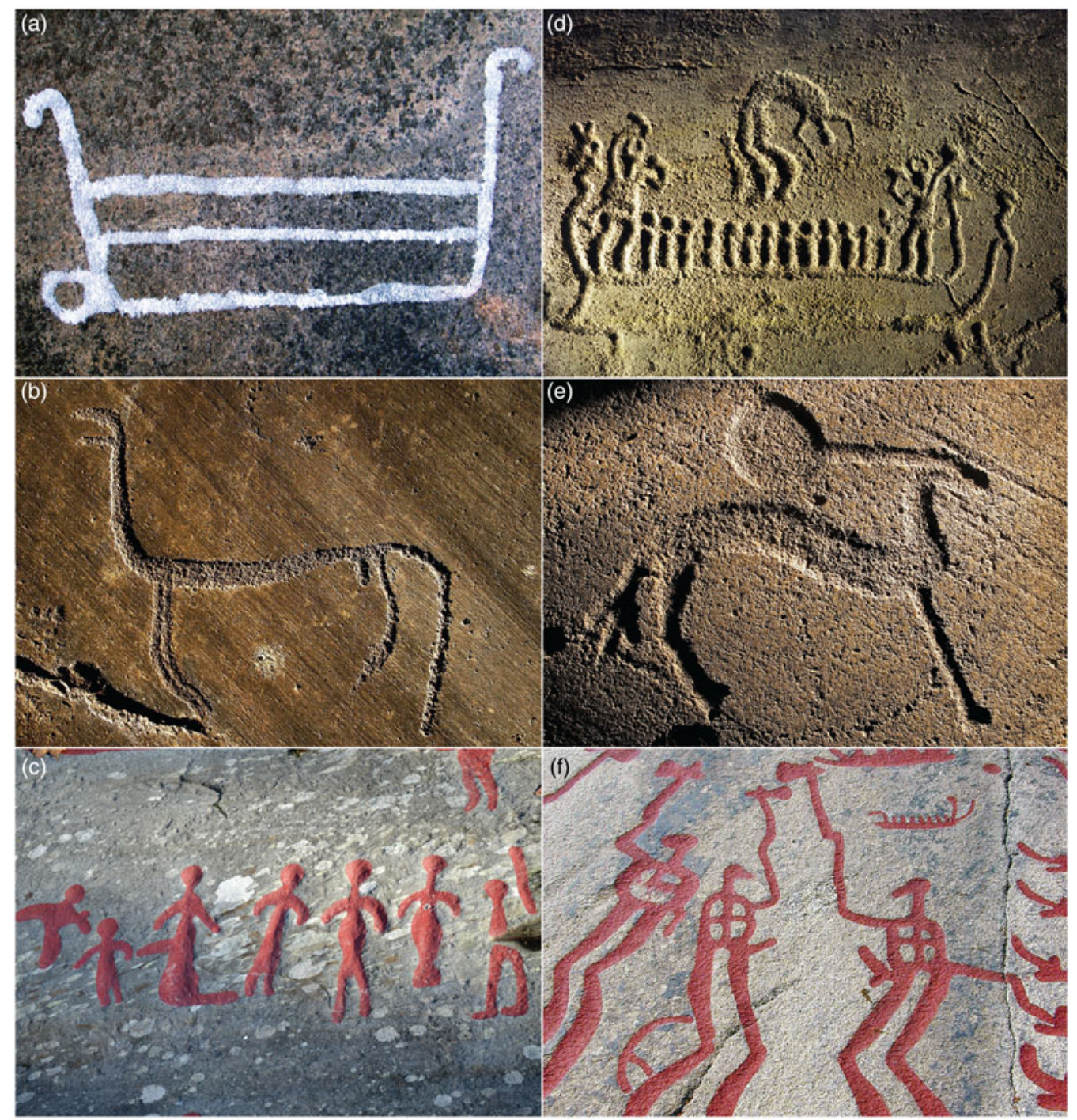

Figure 6. Depictions of basic and subordinate members ( $a, b, d$-f: Tanum; c: Norrköping). (a) SHFA Image ID 4073 (cropped) (Photograph: Toreld Andreas); (b) SHFA Image ID 9144 (Photograph: Ellen Meijer); (c) Image ID 13168 (cropped) (Photograph: Peter Skoglund); (d) SHFA Image ID 1064 (cropped) (Photograph: Bertil Almgren); (e) SHFA Image ID 5908 (Photograph: Ellen Meijer); (f) SHFA Image ID 2026 (Photograph: Åsa Fredell).

defined] as the representation of an event or sequence of events' (Genette 1982, 127). And he further claims that 'as soon as there is an action or an event, even a single one, there is a story because there is a transformation, a transition from an earlier to a later and resultant state' (Genette 1988, 18f). This means that not only would the sentence 'The king died and then the queen died' constitute a narrative, but also simply the sentence 'The king died'. As Prince has remarked, such a minimal definition may capture the difference between narratives and non-narratives, such as book titles, logical syllogisms, or generalizing statements such as 'Elephants are large herbivorous animals'. Still, this definition does not seem to be sufficient for something to be a narrative; examples can easily be found which are about changes of state, but usually are not considered to be narratives (e.g. medical prescriptions, instructions for handling certain tools, or recipes). Furthermore, we should also take into account 


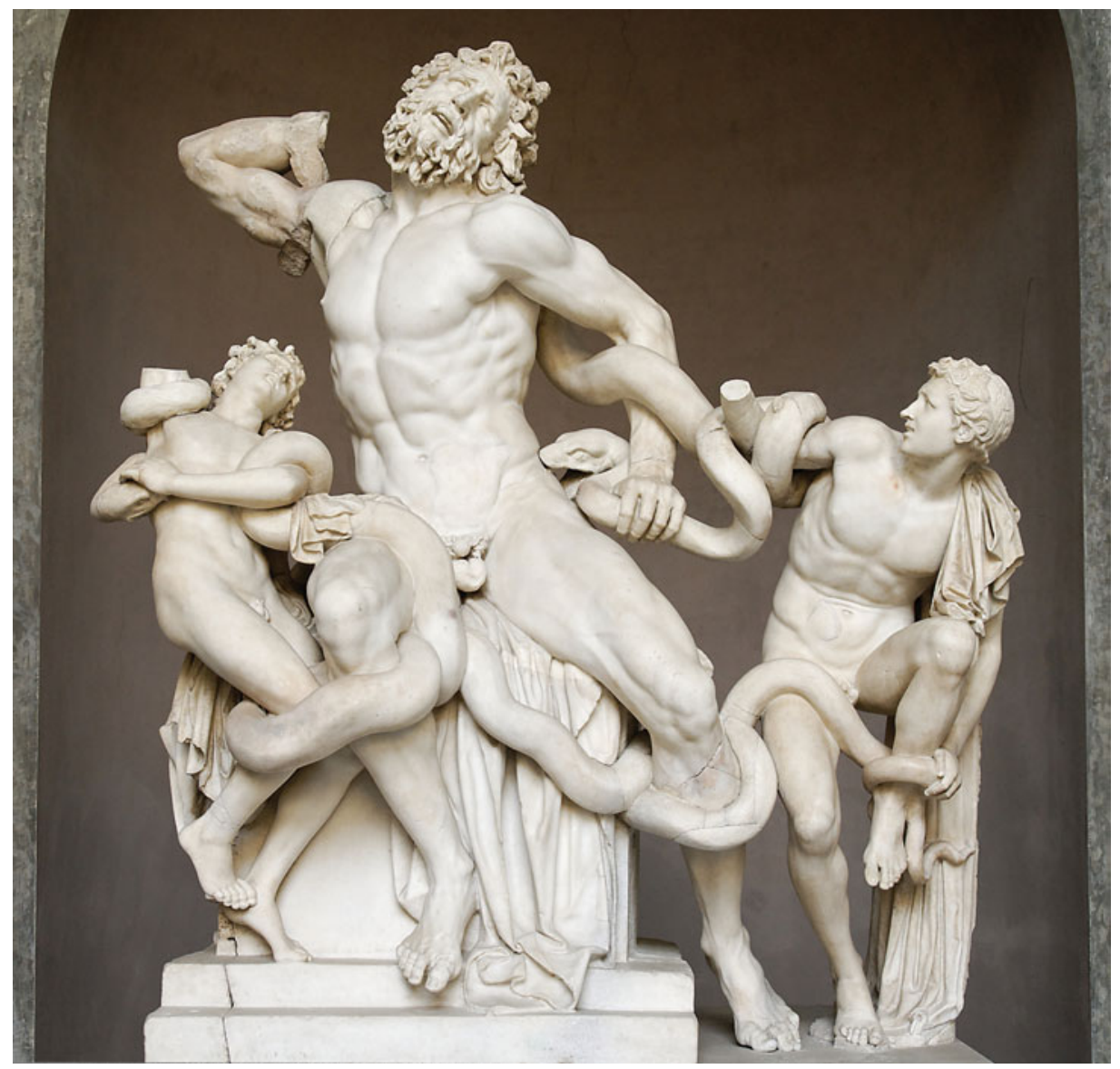

Figure 7. 'Laocoön and his Two Sons', ?first century AD, Vatican Museums, Rome. (Photograph: Marie-Lan Nguyen, https://en.wikipedia.org/wiki/File:Laocoon_Pio-Clementino_Inv1059-1064-1067.jpg)

various degrees of narrativity; some texts are more narrative than others; they are more like plots rather than simple stories (Prince 1999, 43). Indeed, narrative may be regarded as a category with fuzzy boundaries, centring around clear-cut 'stories', or prototypical members, where a rigid and essentialist view could probably be too exclusive (cf. Ranta 2013 and a discussion by Rudrum 2005). Any representation, whether linguistic or not, may have multiple meaning functions or uses depending on socio-cultural, or even idiosyncratic, contexts. Moreover, minimal narratives, as suggested by Genette, may sometimes consist of representations of just single events by implying a past and a present. And among art historians, the narrative potential of monophase pictures has usually been taken for granted, though chiefly from a descriptive, interpretative and historical point of view.

A deeper theoretical account of pictorial narrativity had, however, already been put forward in the eighteenth century by Gotthold Ephraim Lessing ([1766] 1957), where he attempted to outline the characteristic features of painting versus poetry qua signs. According to Lessing, painting can, though to a lesser extent, also display narratives indirectly, namely by depicting the most 'pregnant moment' in a presumed story. A paradigmatic example discussed by Lessing would be the famous Hellenistic sculpture group 'Laocoön and his Two Sons' (probably first century $\mathrm{AD}$ ). A beholder familiar with the myth in question might very well see this sculpture as a significant part of a story. But even without any specific knowledge of the myth, viewers would tend to interpret the scene as a violent struggle, filled with agony, between defending humans and attacking serpents. Quite spontaneously, one might be tempted to reconstruct a minimal, though perhaps sketchy, narrative from the sculpture (see Fig. 7).

Within contemporary psychology, cognitive scientists such as Jerome Bruner (1990) and Roger Schank (1995) have argued that narratives are essential cognitive instruments. Intelligence is, according to Schank, essentially dependent on mental representations of action schemas, that is, generalized sets of expectations about what actions take place in well- 


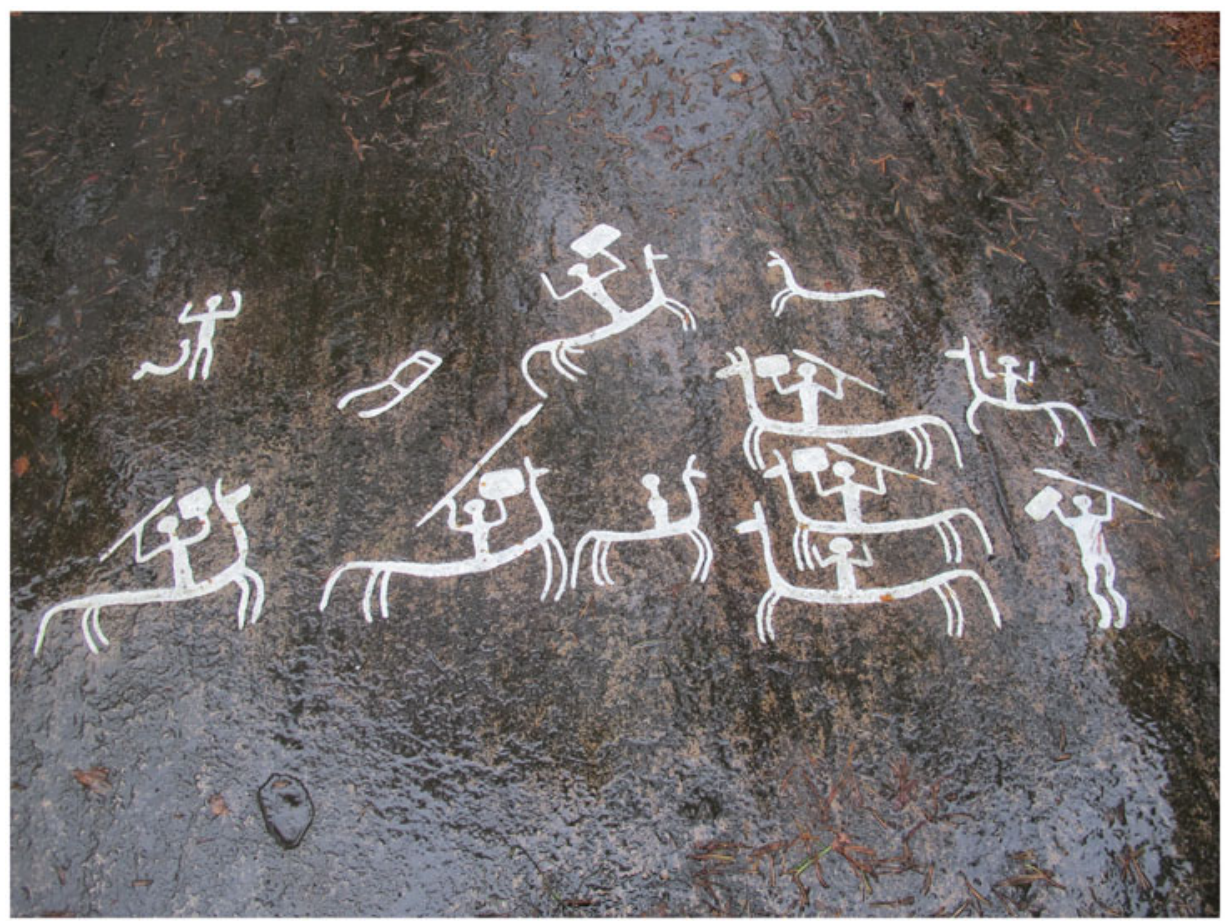

Figure 8. Tegneby, Bohuslän: combat scene with shield-bearing horsemen. (Photograph: Michael Ranta.)

known situations. Furthermore, as Schank suggests, the mental storage of such schemas and narratives occurs frequently in highly abbreviated form, as 'skeleton stories' or as 'gists'. One often does not remember specific narrative instantiations of stories, but rather gists. Thus condensed linguistic utterances can remind us of possible gists, which are then sometimes extended into full-fledged narratives (cf. Ranta 2011; 2013). We would like to claim that pictorial material often functions in a similar way. Pictures may have a quite explicit narrative appearance, but sometimes even highly condensed or indeterminate pictures may generate narrative interpretations, sometimes based on our knowledge of general action schemas.

Actions, just like objects, may be categorized on various levels. Thus minimal narratives of actions may be regarded as belonging to more general categories, termed action schemas, frames, or scripts within cognitive psychology (see e.g. Brewer 1987; Schank \& Abelson 1977). For example, events such as buying a ticket or wearing a black tie may belong to broader categories such as going to the theatre or going to a wedding, which may be further categorized as instances of an entertainment event, or an occasion for joy. Sequences of such stereotypical and categorizable actions incorporate generalized, mentally internalized knowledge about event schemas, such as the order in which specific events will take place; causal, enabling, or conventionalized relations between these events; and what kind of events occur at all in certain action sequences (see e.g. Mandler 1984). Moreover, they may also include mentally stored inventory information, that is, what kinds of objects usually appear in certain situations, and relational information concerning the normal spatial layout of a scene (Mandler 1984, 13-17). Regarding rock carvings, in many cases we may likewise discern a multitude of stereotyped event schemas, such as hunting and combat scenes (Fig. 8).

To take another example, an image of a ship apparently being operated by a crew will arguably belong to a broader action category including the embarkation, the journey and the return of the ship-thus, also single images, as part of wellestablished action schemas, could be interpreted from a narrative perspective.

\section{A case example: fighting a big wild boar}

In the previous sections, we described and discussed some general considerations regarding typification and possible narration of Scandinavian rock carvings. Our claim is that at least minimal narratives consisting of single rendered events or actions can be discerned. However, the question still remains whether rock carvings also display wider and more complex story arcs than just simple ones. In the 
following, we shall focus on a case example found on a rock panel at Himmelstalund, near Norrköping in Sweden.

In this specific location, rock-art sites occur on both sides of the Motala river in a rather restricted area between Lake Glan and the outlet of the river into the Baltic Sea. In the early 1920s, Arthur Nordén studied the rock art in Norrköping. He carried out extensive documentation of various sites, based on comparisons between depicted metal objects and preserved artefacts. He proposed that a majority of the carvings were from the Early Bronze Age (1700-1100 BC: Nordén 1925) and recent analyses seem to confirm this dating (Nilsson 2017). The rock art in Norrköping has been a focus of several PhD studies (Hauptman 2002; Ljunge 2015; Nilsson 2017), but none of these studies focuses in particular on the hunting scenes we are now going to discuss. As part of a larger project on landscape archaeology, Christopher Tilley made a case study of the rock art in Norrköping (Tilley 2008).

Hunting scenes appear at the largest rock-art site in this area, named Himmelstalund, which holds several panels with images representing ships, axes, humans and various animals like bears, elks, horses and boars, just to mention some of the motifs (Hauptman 2002; Ljunge 2015; Nilsson 2017; Nordén 1925; Tilley 2008). A majority of the images at Himmelstalund were probably made in the so-called Montelius periods II and III, i.e. 15001100 BC (Nilsson 2017), and likely the wild boar images are from the same period.

At Himmelstalund, schematized images of wild boars occur in various places, the two most noteworthy being a scene with a boar confronted by two hunters and their dogs, and another consisting of scenes in which herds of wild boars, hunting scenes (a human attacking a wild boar with a spear) and numerous ships occur along a distinctive furrow (Skoglund 2016; 2018). Here we shall turn to the first scene (Fig. 9), which shows a disproportionately large wild boar, a well-known image often reproduced in popular books on rock art due to its expressive and detailed character (e.g. Janson et al. 1989).

Himmelstalund was visited by the authors in August 2017 together with technical assistant Ellen Meijer from the Swedish Rock Art Research Archives. New documentation was carried out, using laser scanning and Structure from Motion (SfM). Nowadays many of the images at Himmelstalund are painted with red colour to improve their visibility, but note that the red colour also tends to fixate perceptual interpretation of the images, whereas laser scanning reveals a more detailed image and is closer to the original image on the rock surface.

The visual display of the Himmelstalund panel invites the viewer to centre the gaze on an oversized wild boar, deeply carved with an enhanced physical, massive presence. The boar's position is directed in profile towards two human hunters, standing to the right in the scene in an attack or defence position, lifting their spears. The spears function as indexical cues pointing towards the boar, and at the same time cue the gaze of the viewer. It is also possible, however, that it is the recognition of these indexical shapes as spears-important and dangerous tools-that catches our attention and directs it to search for a target. Be that as it may, the spears emphasize the presence of the boar, and they seem to reveal an underlying intent of the artist(s) to direct the viewer's focus towards it. Its shape and size signals that it is a massive male boar (as indicated by a phallus), and the spears held in attack position by two humans that it is a group hunt. This is further supported by the accompanying dogs. The role of the dog is crucial in this kind of hunt, since it functions as a lure in order to hold the boar in a position, allowing the hunter to get close to and kill the animal (Magnell 2005, 65).

As mentioned above, 'station points' are determined by the direction in which the artist is imagining the object or landscape, and from which the artist conveyed it onto canvas or rock. Looking at the panel (Fig. 9), we may observe that it implies more than one station point. Sometimes rock carvings may consist of compositions pointing in several different directions, from $0^{\circ}$ to $360^{\circ}$, indicating in one and the same composition several station points that might well be carved by the same artist at one point in time, or by other artists at another point(s) of time in history (Janik 2014, 117). When multiple station points are represented on rock-art panels, an arrested moment is perceivable from several positions. However, in the relatively simple scene we are now studying, only two station points are possible. The wild boar, the two humans and one of the dogs are seen from one station point, while a second dog is depicted from another perspective, deviating $180^{\circ}$ from the first. ${ }^{3}$ If only one station point is assumed, however, the second dog can be seen as lying upside down, i.e. possibly having been injured in the confrontation with the wild boar.

The boar as such indicates that the scene is not referring to hunting schemas in general, but to a specific category of hunting, where bravery and hunting skill are highlighted (as wild boars generally are 


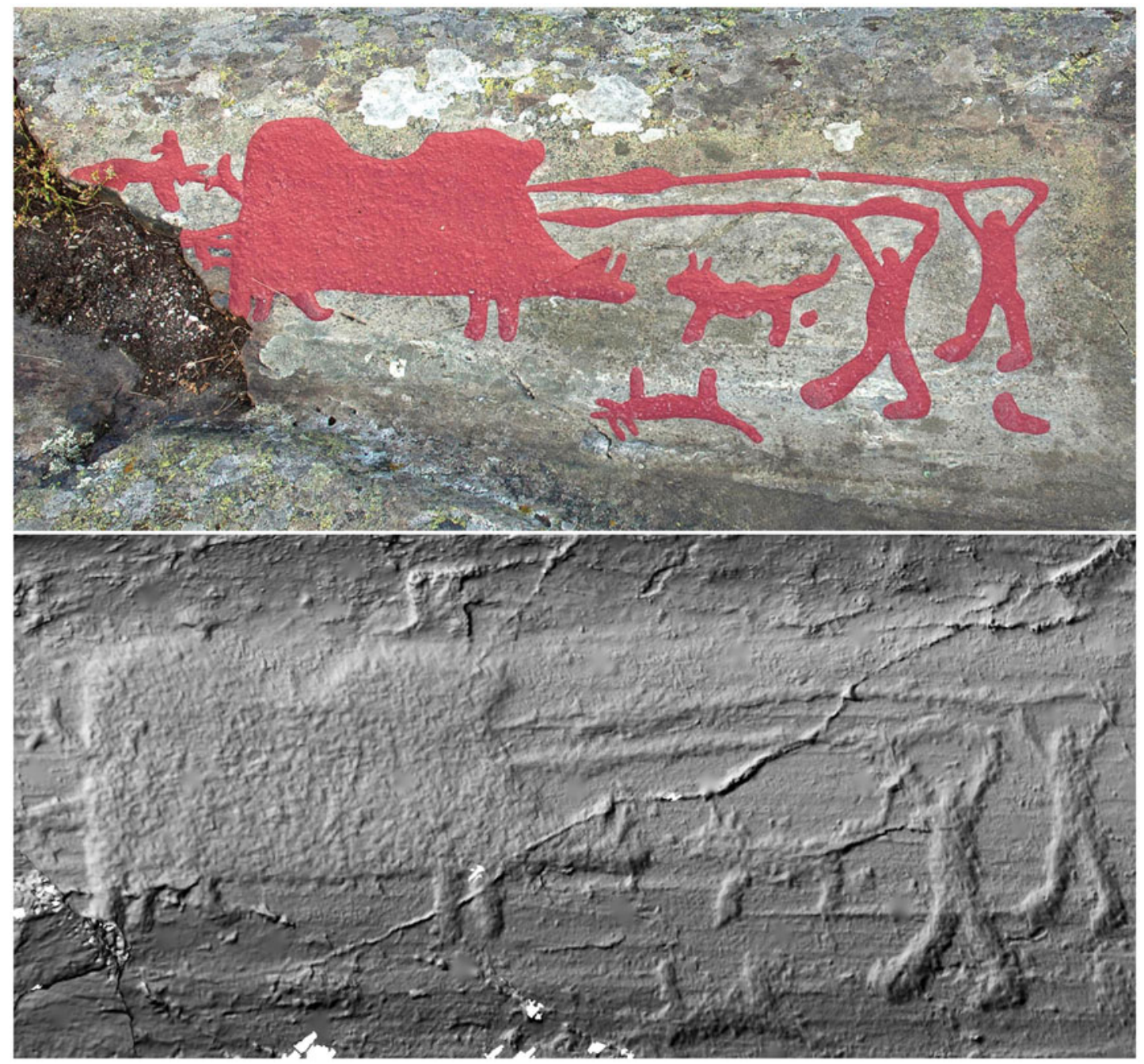

Figure 9. Himmelstalund: panel with human figures fighting a wild boar. (Photograph: Catarina Bertilsson, SHFA Image ID 9052 (cropped); laser scanning: Ellen Meijer, SHFA.)

more dangerous than, for example, elk and deer). A stressed or hurt wild boar is a dangerous animal that is even more likely to attack hunters and also to kill hunting dogs (Magnell 2005, 66). Moreover, considering Rosch's view on categorization, we might regard this as a specific kind of boar, clearly potentially ferocious with its magnitude and almost supernatural qualities, hence perhaps rather belonging to a specific, subordinate (mythological) category than to the basic category of pigs, comparable to e.g. the sun-horse referred to earlier. Likewise the two humans with their spears may refer to yet another subordinate category, namely hunters rather than humans in general, as indicated by the spears held by the agents, in a rather specific situation with narrative potential.

Indeed, the wild boar has been part of ancient mythologies in numerous European cultures, such as among the Greeks, the Celts and the Romans (Green 1992). For example, in the well-known epic of Odysseus, his status as a hero is underlined by the fact that as a young man he was involved in a fight with a wild boar, which he defeated alone without help from fellow hunters. The killing of the boar contributed to establishing Odysseus' status as a brave hunter and warrior (Levaniouk 2011). It seems, then, that this motif has a long-standing tradition, of which the rock carving at Himmelstalund might just be a further instantiation, demonstrating the importance of wild boar hunting as a means to achieve glory and fame in a Bronze Age culture (Skoglund 2016; 2018).

Furthermore, it can be argued that the scene does not only represent a single event as such (the killing of a wild boar), but it is also part of a stereotypically shared action schema, as referred to earlier. 


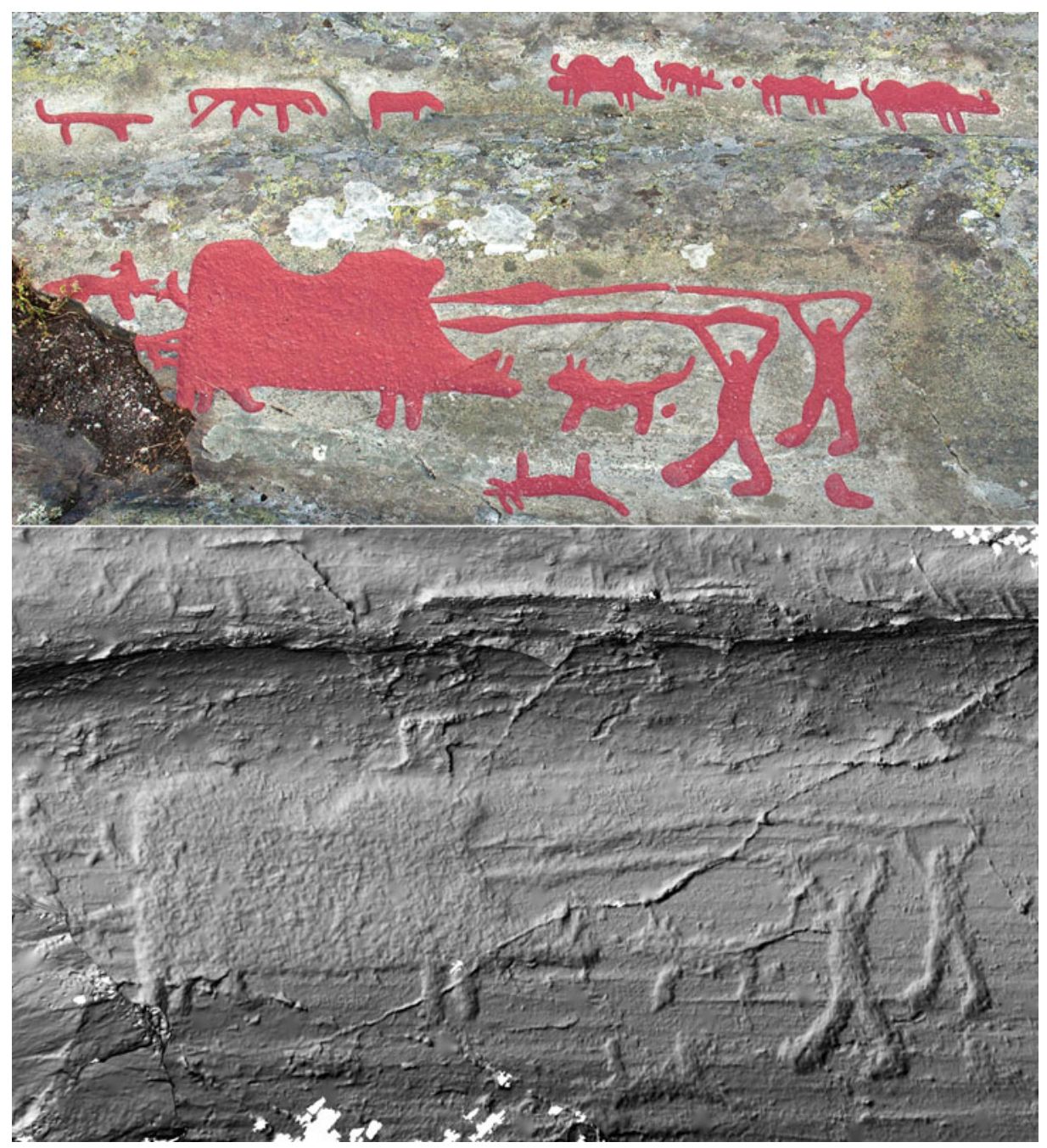

Figure 10. Himmelstalund: extended panel with human images fighting a wild boar. (Photograph: Catarina Bertilsson, SHFA Image ID 9052; laser scanning: Ellen Meijer, SHFA.)

For a person familiar with hunting, this single event (and indeed pregnant moment; cf. Figure 7), would presuppose a sequence of events, taking place before, and after, the actual killing of the animal. The killing scene is thus part of a larger chain of events involving e.g. the tracking of the animal before the killing and slaughtering the animal afterwards. From this perspective, the hunting scene represents a minimal narrative. However, there is further possibility worth considering, involving the surrounding context. Close to this scene there are one, or two, additional clusters of images (Fig. 10), and one may very well ask whether the clusters might be related.

The upper cluster(s) consist of six animals moving from left to right, and seemingly a small ship, with two or possible three people aboard, turned upside down in relation to the animals, which thus implies another station point. ${ }^{4}$ Within the configuration, a group of four animals to the right is slightly separated from the other two and the possible vessel to the left. These four animals show resemblance to the large wild boar below, having a similar kind of hump on the back, snouts with tusks, all four legs depicted, and a short tail. The two animals to the left, on the other hand, have straight backs and only two legs are visible; altogether these traits make them similar to the two hunting dogs near the oversized wild boar underneath.

The dogs might perhaps be assumed to be tracking down the wild boars, as a prelude to the scene below. Does this upper scene belong to the latter scene; is it depicting a scene preceding the fight, succeeding it, or are both perhaps taking place simultaneously? Possibly the scene with the herd of wild 
boars could be interpreted as the equivalent to an 'establishing shot' in a film, showing the entry to the unfolding event. The top scene is depicted in a way that the motifs seem to be distant (where size in relation to the oversized boar is the most obvious clue), similar to an opening scene in a film, where a wider shot is followed by close-ups showing more detail. If so, we can interpret the scene as showing a herd of wild boars that is followed by hunting dogs, where this initial tracking of boars leads to the final confrontation scene.

From this perspective we are not only dealing with one minimal narrative - a single event-but with a narrative involving a sequence of different, though related, events. Relating the two scenes to each other, the images seem to constitute a more expanded story, i.e. a particular sequence of related events.

Further support for an at least minimal narrative interpretation (e.g. wild boar hunting) can be found when scenes are recurring, and thus can be validated as a theme when it comes to relating images (e.g. spears, people and boars). Somewhat similar hunting scenes also occur at another panel at Himmelstalund. On this panel there are two groups of boars intermixed with one and three humans respectively. In the first case a man is holding a spear in an attack position pointing towards the back of a boar. In the second case a person is actually thrusting what seems to be a spear into the back of a boar. In this scene, there are also two other humans, although without weapons.

In concluding this section, we should emphasize that far from all Scandinavian rock carvings seem to display narrative structures, at least not obvious ones, including those at Himmelstalund. In numerous cases, non-iconic forms (such as cup marks) and rather abstract patterns (such as so-called sun crosses or frame-shaped figures with zigzag lines; cf. Figure 11a) occur. In other cases, images of concrete objects such as swords, axes, animals and innumerable ships (cf. Figure 11b) are simply 'lined up', almost as some kind of inventory of possessions or resources. Furthermore, narrative links to nearby motifs can often not be identified. Admittedly, simple depictions of tools and weapons can imply possible activities, as can ships. Ships indicate an instrumental capacity for enabling journeys, i.e. transitory and temporal events. But as such, without any depictions of involved agents, or external interpretative clues or instructions, it would be too far-fetched to ascribe these latter carvings any concrete narrative functionality, contrary to our earlier example with the wild boar hunt. Narrative interpretations ought to be restricted and well founded; otherwise, the very concept of narrativity would be at risk of becoming vacuous.

\section{Conclusions: prospects of a narratological analysis}

As stated in the introduction of this paper, our approach may facilitate and suggest a more focused account of narrative aspects in Scandinavian rock art. Hence we might sum up our suggestions as follows:

\section{(a) A broadening of the narrative corpus in Scandinavian rock art}

Focusing on a small sample, we have elaborated the possibility of defining rock-art images, and sequences of images, as having narrative qualities based on insights made within cognitive science and narratology.

As the examples above show, it appears that in many cases it is indeed possible to identify pictorial constellations of certain objects or subjects as at least minimal narratives. In Scandinavian rock-art studies, the concept of narrative is often reserved for panels displaying scenes which are linked to each other by the same subject being repeated, indicating that the various scenes are related to each other in a narrative sequence. However, the theoretical concepts applied in our study broadens this view.

\section{(b) A differentiation of various kinds of narrative structures in Scandinavian rock art}

A narrative analysis of petroglyphs might strive for the identification of pictorial renderings of:

(i) single events and implied action schemas, understood as changes of state, usually performed by (several or single) agents;

(ii) stories, i.e. more complex, causally or narratively connected event sequences that are fictional or historically situated and presumably (re-)told for e.g. ideological or social purposes; and

(iii) master-narratives or 'umbrella myths', which permeate multiple instances of storytelling within a culture, and which provide and consolidate cosmological explanations and social structures (as suggested by e.g. Gjerde 2010; Goldhahn 2016).

\section{(c) The establishment of a set of criteria for identifying narrative structures in rock art}

Foremost, we regard the following aspects as fruitful and worth considering in building up a narrative analysis of rock art, from a bottom-up perspective:

(i) The identification of typified objects and subjects: Generally and historically speaking, we might 


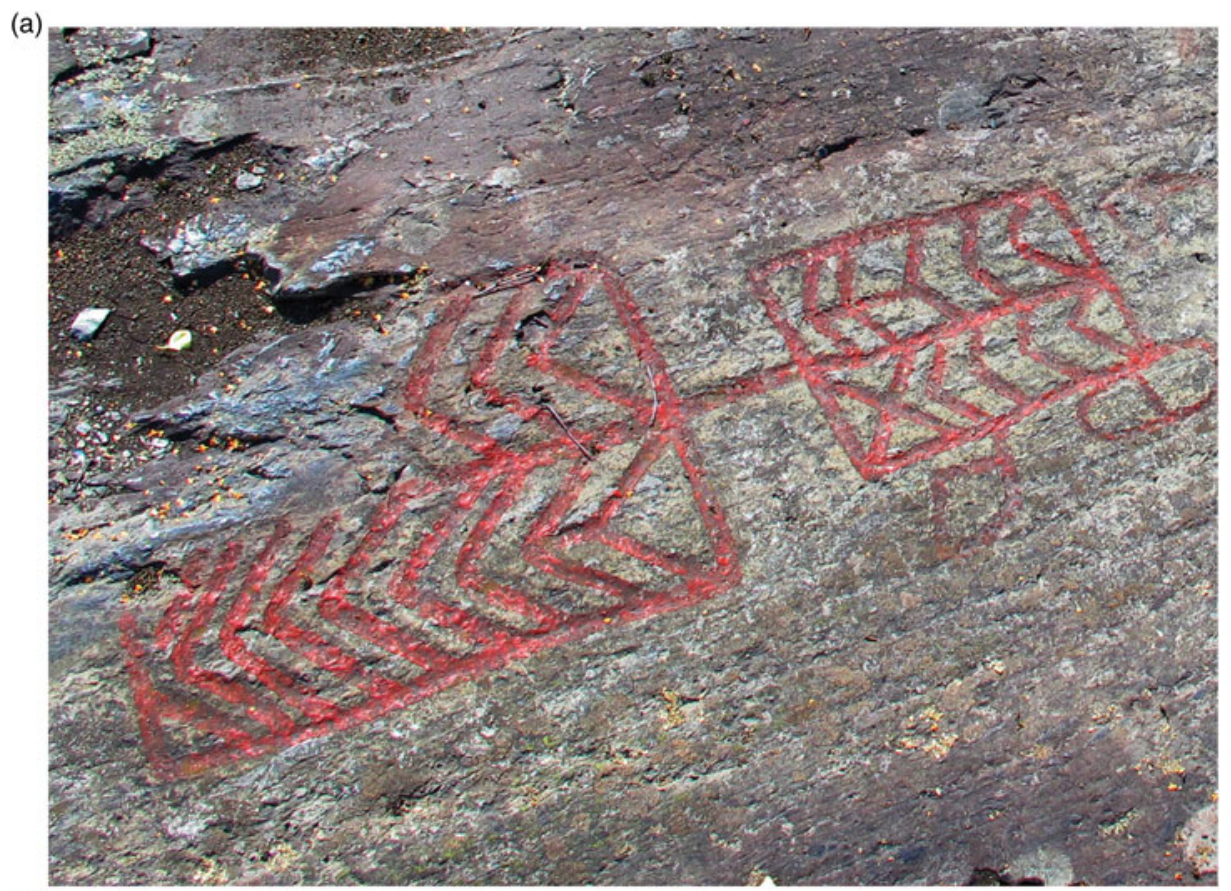

(b)

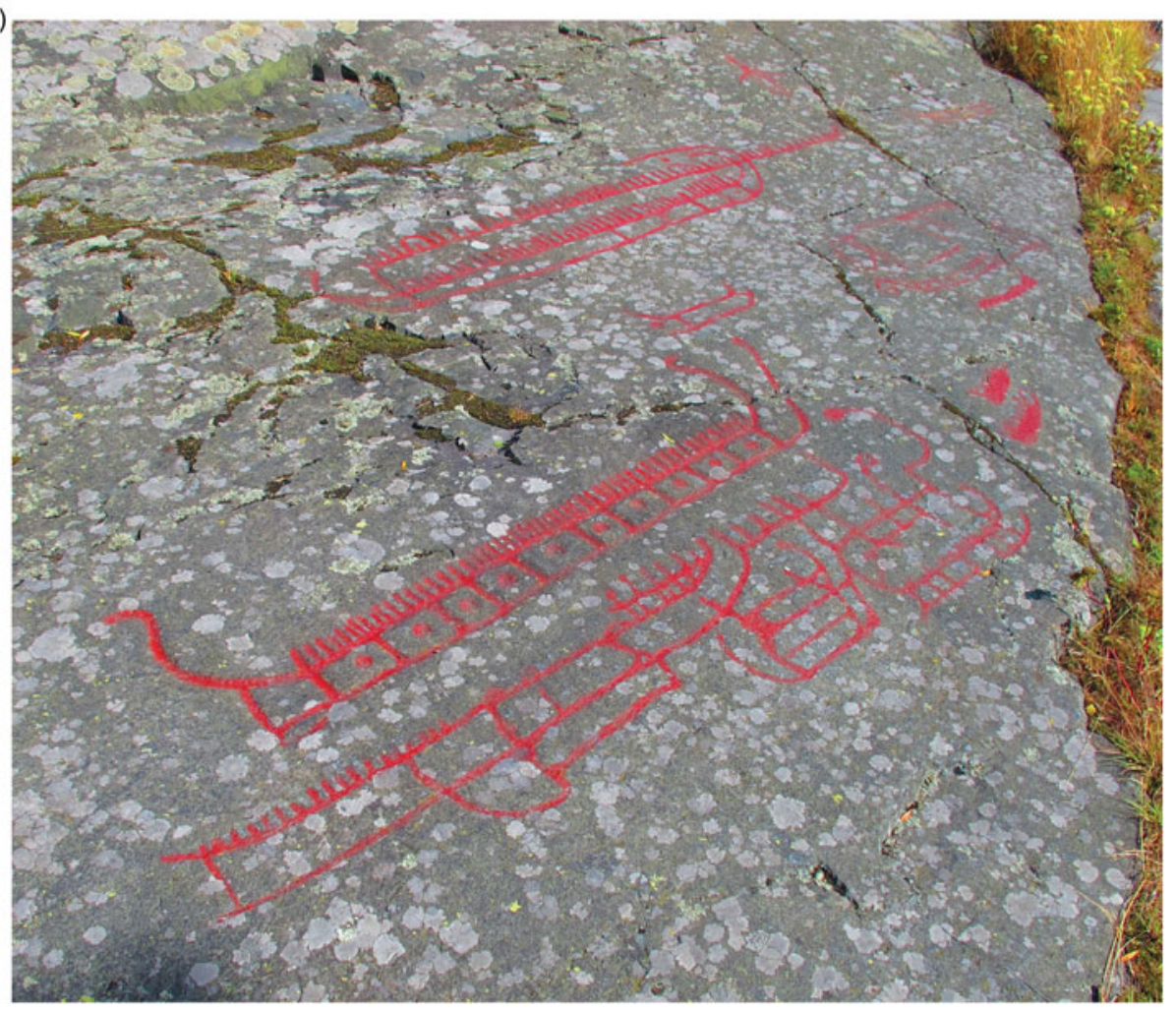

Figure 11. Himmelstalund: (a) two frame-shaped figures with zigzag lines; foot sole; (b) ships. (Photographs: Michael Ranta.)

assume that an important task of artists appears to have been to be able to abstract and visualize those types of subjects which can be recognized and appreciated by a larger public. As we may recall, it seems that the overall perceived shape frequently functions as a cue for determining category membership. In cases of categorization based upon shape-cues, mostly basic-level categories are established, though also sometimes subordinates. Renderings of e.g. humans, 
animals, trees and landscapes made within the most shifting cultural contexts quite often show cross-cultural comprehensibility. In fact, this might also reinforce any argument suggesting that petroglyphs are mainly iconic signs, based on (perceived) similarity with the objects they stand for. In our case, this is especially notable, one might suspect, when it comes to biological types, such as humans and animals, perhaps also certain tools or weapons. Is this relative conformity a pure coincidence? We do not think so; rather, we should be prepared to assume that there are (basic-level) types of objects which have a general human significance, the rendering of which is constrained by our biologicalperceptual presuppositions and, indeed, perceptual-physical characteristics of the represented objects. So, a reasonable first step for a narrative analysis of rock art would then consist of the identification of obvious, non-controversial representations and signs of the objects and subjects constituting the primary building blocks of a presumed story.

(ii) The identification of typified actions: One further step of approaching narrativity in rock art is by attempting to identify sequences of stereotypical and categorizable actions. These action schemas or scripts incorporate generalized and mentally internalized knowledge as to the order in which specific events will take place and also causal or conventionalized relations between these events. Here we have demonstrated how this concept can be used on a hunting scene, but the concept could also be extended to other actions like, for example, combats or fighting scenes. The concept of frames or scripts therefore opens up the possibility of also regarding rather simple actions or events as mini-narratives, implicitly stretching backwards and forward in time, the identification of which in many cases also might be relatively straightforward.

(iii) The identification of possible station points: The idea of station points (Janik 2014) helps us to follow the creators' intentions for how to look at the images. Different station points will direct the viewer to comprehend the images from various perspectives. A story, or stories, evolve(s) in accordance with the specific perceptual perspective of the rock artist(s), thereby implicitly guiding the viewer's comprehension. A set of images is ordered by different station points due to the fact that some visual cues are more salient for perception than others. A marker of this fact in Figures $9 \& 10$ is the size and prominence given to the wild boar on the panel. Moreover, we may have a possible 'establishing' scene at the top of the panel showing a panorama of animals (wild boars and dogs), to which the massive wild boar in the fighting scene might refer. This way of interpreting the scenes as being part of an on-going story is a technique used many times in film (and literature), where flash-forwards and flash-backs take the viewer forwards and backwards in time (Rédei 2012).

In this paper, we have, by considering cognitive, semiotic and narratological approaches, demonstrated the basic narrative potential in rock art. As the sample is small, our results cannot be generalized to cover all south Scandinavian rock art. Obviously much rock art consists simply of non-narrative displays of images, as exemplified by Figures 11a \& b, which seemingly have no narrative content, nor narrative links to other surrounding motifs.

Still, we regard the results as promising. The hunting scene we have chosen to analyse is by no means unique; similar examples of simple events or mini-stories can be identified in many places. In the future, one might expand our current approach in order to investigate whether there are also examples of more elaborated narratives involving several sequences of events. The methodological, and more foundational, proposal outlined in this study can thus reasonably be extended to more complicated narrative structures as well.

\section{Notes}

1. In experimental studies, averaged shapes were created by taking superimposed shapes of objects, from which an average outline of the overlapped figures was drawn (see Rosch \& Lloyd 1978, 34). For petroglyphs as the rendering of types or gestalts, and a general discussion of Gestalt theory, see Stebergløkken (2016).

2. Cf. https://plato.stanford.edu/entries/events/(retrieved 22 January 2018).

3. We might also mention that another important visual component in the 'method of seeing' is the so-called picture plane. The latter is the plane where events, actions and agents are located on a pretend surface or spatial context. Picture planes, according to Janik, are, however, absent in rock art $(2014,118)$.

4. In general, ships tend to be larger than this example, but a similar small ship appears for example on top of Slab No 6 in the Sagaholm mound; cf. Goldhahn $(1999,55)$.

\section{Acknowledgements}

This article has been written as part of the project StoRock (Storytelling in Rock Art), financed by the Swedish 
Research Council (Grant no. 2016-01288), to which we hereby would like to express our gratitude. This paper is partly based on observations the authors made during a field trip to the rock-art sites at Norrköping in August 2017. The visit to Norrköping was undertaken together with Ellen Meijer, from the Swedish Rock Art Research Archives (SHFA), who made the laser scans used in this paper, and we wish to thank her for her participation.

Michael Ranta Sichuan University College of Literature and Journalism Chengdu China $\mathcal{E}$

Division of Cognitive Semiotics Department of Language and Literature Lund University Box 201 SE-221 00 Lund Sweden Email:michael.ranta@semiotik.lu.se m.ranta31@gmail.com

Peter Skoglund Division of Archaeology Department of Cultural Sciences Linnaeus University SE-391 82 Kalmar Sweden

Email: peter.m.skoglund@lnu.se

Anna Cabak Rédei Division of Cognitive Semiotics Department of Language and Literature Lund University Box 201 SE-221 00 Lund Sweden Email:anna.cabak_redei@semiotik.lu.se

Tomas Persson Division of Cognitive Science Department of Philosophy Lund University Box 192 SE-221 00 Lund Sweden Email: tomas.persson@lucs.lu.se

\section{References}

Bednarik, R., 2012. Dating and taphonomy of Pleistocene rock art. Bulletin de la Société Préhistorique AriègePyrénées (65-66), 188-9.

Bertilsson, U., 2015. From folk oddities and remarkable relics to scientific substratum: 135 years of changing perceptions on the rock carvings in Tanum, northern Bohuslän,
Sweden, in Picturing the Bronze Age, eds. P. Skoglund, J. Ling \& U. Bertilsson. Oxford: Oxbow, 5-20.

Brewer, W.F., 1987. Schemas versus mental models in human memory, in Modelling Cognition, ed. P. Morris. Chichester (NY): John Wiley \& Sons, 187-97.

Bruner, J., 1990. Acts of Meaning. Cambridge/London: Harvard University Press.

Bryson, N., 1983. Vision and Painting - The logic of the gaze. London: Macmillan.

Eco, U., 1976. A Theory of Semiotics. Bloomington (IN): Indiana University Press.

Fredell, Å., 2003. Bildbroar: figurativ bildkommunikation av ideologi och kosmologi under sydskandinavisk bronsålder och förromersk järnålder [Pictorial bridges: figurative pictorial communication of ideology and cosmology during the south Scandinavian bronze age and pre-Roman iron age]. PhD thesis, Göteborgs universitet.

Fredell, A., 2006. The Pangs in Askum? An example of storytelling by rock pictures and their possible link to a known story, in Anthropology of the IndoEuropean World and Material Culture. Proceedings of the 5th International Colloquium of Anthropology of the Indo-European World and Comparative Mythology, eds. M.V. Garcia Quintela, F.J. Gonzales Garcia \& F. Criado Boado. Budapest: Archaeolingua, 121-38.

Genette, G., 1982. Frontiers of narrative, in Figures of Literary Discourse, by G. Genette (trans. A. Sheridan). New York (NY): Columbia University Press, 127-44.

Genette, G., 1988. Narrative Discourse Revisited (trans. J. E. Lewin). Ithaca (NY): Cornell University Press.

Gjerde, J.M., 2010. Rock Art and Landscapes: Studies of Stone Age rock art from northern Fennoscandia. PhD thesis, Universitetet i Tromsø.

Goldhahn, J., 1999. Sagaholm: hällristningar och gravritual [Sagaholm: rock carvings and grave ritual]. $\mathrm{PhD}$ thesis, Umeå universitet.

Goldhahn, J., 2016. Sagaholm: North European Bronze Age rock art and burial ritual. Oxford: Oxbow.

Goldhahn, J. \& J. Ling, 2013. Bronze Age rock art in northern Europe: contexts and interpretations, in The Oxford Handbook of the European Bronze Age, eds. H. Fokkens \& A. Harding. Oxford: Oxford University Press, 270-90.

Goodman, N., 1976. Languages of Art - An approach to a theory of symbols. Indianapolis (IN): Hackett Publishing.

Green, M., 1992. Animals in Celtic Life and Myth. London: Routledge.

Hagen, M.A., 1986. Varieties of Realism. Geometries of representational art. Cambridge: Cambridge University Press.

Hauptman, K., 2002. Bilder av betydelse: hällristningar och bronsålderslandskap i nordöstra Östergötland [Meaningful pictures: rock carvings and bronze age landscapes in northeastern Östergötland]. PhD thesis, Stockholms Universitet.

Helskog, K., 2012. Bears and meanings among hunterfisher-gatherers in northern Fennoscandia 90002500 BC. Cambridge Archaeological Journal 22(2), 209-36. 
Janik, L., 2014. Seeing visual narrative. New methodologies in the study of prehistoric visual depictions. Archaeological Dialogues 21, 103-26.

Janson, S., E.B. Lundberg, \& U. Bertilsson (eds.), 1989. Hällristningar och hällmålningar i Sverige [Rock carvings and rock paintings in Sweden]. Stockholm: Forum.

Kaul, F., 1998. Ships on Bronzes: A study in Bronze Age religion and iconography. Copenhagen: National Museum.

Kaul, F., 2005. Bronze Age tripartite cosmologies. Praehistorische Zeitschrift 80(2), 135-48.

Kristiansen, K., 2010. Rock art and religion, in Representations and Communications: Creating an archaeological matrix of late prehistoric rock art, eds. A. Fredell, K. Kristiansen \& F. Criado Boado. Oxford: Oxbow, 92-115.

Lakoff, G., 1987. Women, Fire, and Dangerous Things - What categories reveal about the mind. Chicago (IL): University of Chicago Press.

Lessing, G.E., [1766] 1957. Laocoon: An essay on the limits of painting and poetry. New York (NY): Noonday Press.

Levaniouk, O., 2011. Eve of the Festival: Making Myth in Odyssey 19. (Hellenic Studies Series 46.) Washington (DC): Center for Hellenic Studies. http://nrs.harvard.edu/urn-3:hul.ebook:CHS_Levaniouk. Eve_of_the_Festival.2011 (retrieved 6 March 2018).

Ling, J., 2012. War canoes or social units? Representation in rock-art ships. European Journal of Archaeology 15(3), 465-85.

Ljunge, M., 2015. Bortom avbilden: sydskandinaviska hällbilders materialitet [Beyond depiction: the materiality of south Scandinavian rock images]. $\mathrm{PhD}$ thesis, Stockholms universitet.

Magnell, O., 2005. Tracking Wild Boar and Hunters: Osteology of wild boar in Mesolithic South Scandinavia. PhD thesis, Lunds universitet.

Mandler, J.M., 1984. Stories, Scripts, and Scenes: Aspects of schema theory. London/Hillsdale: Lawrence Erlbaum.

Melheim, L., 2013. An epos carved in stone: three heroes, one giant, and a cosmic task, in Counterpoint: Essays in archaeology and heritage studies in honour of Professor Kristian Kristiansen, eds. S. Bergerbrant \& S. Sabatini. Oxford: Archaeopress, 273-82.

Nilsson, P., 2017. Brukade bilder: södra Skandinaviens hällristningar ur ett historiebruksperspektiv [Images in use: south Scandinavian rock art from a uses of the past perspective]. PhD thesis, Stockholms universitet.

Nordén, A., 1925. Östergötlands bronsålder I-II [The bronze age of Östergötland I-II]. PhD thesis, Uppsala universitet.

Palmer, S.E., E. Rosch \& P. Chase, 1981. Canonical perspective and the perception of objects, in Attention and Performance IX, eds. J. Long \& A. Baddeley. Hillsdale (NJ): Lawrence Erlbaum. 135-51.

Prince, G., 1982. Narratology: The form and functioning of narrative. Berlin: Mouton.
Prince, G., 1999. Revisiting narrativity, in Grenzüberschreitungen: Narratologie im Kontext [Transcending boundaries: narratology in context], eds. W. Grünzweig \& A. Solbach. Tübingen: Narr, 43-51.

Ranta, M., 2000. Mimesis as the Representation of Types - The historical and psychological basis of an aesthetic idea. Stockholm: Stockholm University.

Ranta, M., 2011. Stories in pictures (and non-pictorial objects) - a narratological and cognitive psychological approach. Contemporary Aesthetics 9. http:// www.contempaesthetics.org/newvolume/pages / article.php?articleID $=619 \&$ searchstr $=$ ranta (retrieved 6 March 2018).

Ranta, M., 2013. (Re-)creating order: narrativity and implied world views in pictures. Storyworlds: $A$ Journal of Narrative Studies 5, 1-30.

Rédei, A.C., 2012. Towards a cognitive semiotic approach to cinema: semiotics vs. 'semiology', in Proceedings of the 10th World Congress of the International Association for Semiotic Studies (IASS/AIS). A Coruna: Universidade da Coruña, 895-90.

Rosch, E., 1994. Categorization, in Encyclopedia of Human Behavior 1, ed. V.S. Ramachandran. San Diego (CA): Academic Press, 513-23.

Rosch, E. \& B.B. Lloyd (eds.), 1978. Cognition and Categorization. Hillsdale (NJ): Lawrence Erlbaum.

Rosch, E. \& C.B. Mervis, 1975. Family resemblances: studies in the internal structure of categories. Cognitive Psychology 7, 573-605.

Rudrum, D., 2005. From narrative representation to narrative use: towards the limits of definition. Narrative 13(2), 195-204.

Schank, R.C., 1995. Tell Me a Story-Narrative and intelligence. Evanston (IL): Northwestern University Press.

Schank, R.C. \& R.P. Abelson, 1977. Scripts, Plans, Goals and Understanding. Hillsdale (NJ): Lawrence Erlbaum.

Skoglund, P., 2016. Rock Art Through Time: Scanian rock carvings in the Bronze Age and earliest Iron Age. Oxford: Oxbow.

Skoglund, P., 2018. The wild boar in Scandinavian rock art, in Giving the Past a Future: Essays in archaeology and rock art; studies in honour of Dr. Phil. h.c. Gerhard Milstreu, eds. J. Dodd \& E. Meijer. Oxford: Archaeopress, 112-20.

Skoglund, P., J. Ling, \& U. Bertilsson (eds.), 2015. Picturing the Bronze Age. Oxford: Oxbow.

Sonesson, G., 1989. Pictorial Concepts. Lund: Lund University Press.

Stebergløkken, H., 2016. Bergkunstens Gestalter, Typer og Stiler: En Metodisk og Empirisk Tilnærming til Veidekunstens Konstruksjonsmåter $i$ et Midtnorsk perspektiv [The forms, types, and styles of rock art: A methodical and empirical approach to early rock art's construction methods from a central-Norwegian perspective]. PhD thesis, NTNU Trondheim.

Tilley, C.Y., 2008. Body and Image: Explorations in landscape phenomenology 2. Walnut Creek (CA): Left Coast Press. 


\section{Author biographies}

Michael Ranta is currently a research fellow at the College of Literature and Journalism, Sichuan University, Chengdu, China as well as at the Division of Cognitive Semiotics, Lund University. He holds a PhD and is an Associate Professor in the History of Art from Stockholm University, Sweden. His primary research interests include cognitive psychology, art history, narratology, semiotics, and aesthetics.

Peter Skoglund is a lecturer at the Linnaeus University in Kalmar, Sweden. $\mathrm{He}$ is an Associate Professor in Archaeology and he has published several papers on Scandinavian rock art. His research interests includes rock-art chronology and landscape archaeology, topics which he discusses in the book Rock Art Through Time (Oxbow, 2016).
Anna Cabak Rédei, $\mathrm{PhD}$ in semiotics, Reader in Cognitive Semiotics at Lund University, Sweden. She is a researcher at Lund University and external lecturer in Philosophy of Science at Copenhagen Business School, Denmark. She wrote her dissertation in (cultural) semiotics (2007) studying Germain de Staël's travel accounts in the wake of the French Revolution. She is interested in narrativity, cognition, psychology, history of ideas, film and pictorial semiotics.

Tomas Persson is a research fellow and lecturer in Cognitive Science at Lund University and wrote his doctoral thesis (Lund University, 2008) on the topic of what minimal cognitive requirements might be needed for pictorial abilities, instantiated by animals' behaviours in relation to pictures. Pictorial semiotics was central for this work. His further research has focused on planning, imagination and social synchronization in great apes and other mammals. 